\title{
A chemical method of the production of "heavy" sodium tripolyphosphate with the high content of Form I or Form II
}

\author{
Marcin Banach, Zygmunt Kowalski, Zbigniew Wzorek, Katarzyna Gorazda \\ Cracow University of Technology, Institute of Inorganic Chemistry and Technology, ul. Warszawska 24, 31-155 Kraków, \\ Poland, e-mail: marcinbanach@chemia.pk.edu.pl
}

\begin{abstract}
Sodium tripolyphosphate STPP is used in laundry detergent as a detergent „builder”. The paper presents the chemical method of obtaining ,heavy”, i.e. with higher bulk density granulated sodium tripolyphosphate. The bulk density of sodium tripolyphosphate was increased by preparing a mixture of the dried sodium phosphates, the recycled subgrain of STPP and water in specific proportions and calcining this mixture for 1 hour at $400^{\circ} \mathrm{C}$ and $550^{\circ} \mathrm{C}$ (to obtain a proper STPP form) in the chamber kiln. This method allows producing the granular sodium tripolyphosphate with high bulk density $\left(1.04-1.07 \mathrm{~kg} / \mathrm{dm}^{3}\right)$ and a high content of Form I or Form II, respectively.
\end{abstract}

Keywords: sodium tripolyphosphate, high bulk density, granular product.

\section{INTRODUCTION}

The annual consumption of phosphate containing detergents in Europe amounts to about 1.8 million tonnes ${ }^{1}$. The type of phosphate most commonly used is sodium tripolyphosphate (STPP) ${ }^{2-4}$. STPP performs several useful functions in the process of washing and cleaning ${ }^{5-7}$. It:

- intensifies surfactants to wash effectively by the sequestration of the ions of calcium and magnesium in hard water and dirt,

- prevents the re-deposition of dirt on fabrics,

- buffers the $\mathrm{pH}$ of the washing solution and dissolves and disperse dirt particles,

- hydrolyses greases and oils facilitating their removal,

- facilitates the dissolving and rinsing off detergents.

The other single builder, which performs the same functions as sodium tripolyphosphate has never been found ${ }^{8}$. The life cycle analysis confirms the smaller harmfulness of sodium tripolyphosphate for the environment than in the case of zeolite A (the often applied substitute of STPP) 9 .

Compact powders are at $1 / 3$ more concentrated than the previous standard detergents ${ }^{10,11}$. The modern compact powders are an advantage for the environment because they mark the lower consumption of raw materials and the lower load of surfactants ${ }^{12,13}$. The tablets are easy to use, allowing avoiding the problem of spillage during the use and prevent the usage of too much or too little of the detergent ${ }^{14,15}$.

Production of compact detergents requires the implementation of STPP with the specific bulk density, particle size distribution, crystalline phase (Form I, Form II or hexahydrate forms) and moisture contents ${ }^{16,17}$. The STPP bulk density and particle size distribution influence the bulk density, the granulation and the absorptivity of the surfactants of the produced detergent. Moisture and the content of the crystalline STPP have an influence on dissolving the detergents and the viscosity of the washing solution. Form I hydrates quickly and may cause lumping of the powders. The parameter deciding about the content of Form I and Form II in the STPP product is its calcining temperature ${ }^{16-18}$.
STPP obtained with the classic two-stage method has the bulk density $\sim 0.54 \mathrm{~kg} / \mathrm{dm}^{3}$, because after spray-drying sodium phosphates and STPP occur in the form of small „empty shells”. Milling of the sodium tripolyphosphate is the simplest way of increasing the bulk density to the level of $0.85 \mathrm{~kg} / \mathrm{dm}^{3}$, however the product is the fine-grained powder.

In order to obtain the „heavy” product, STPP powder from the two-stage production method is compacted, after adding some quantity of water, with the roll presses under very high pressure, then milled and separated into grain fraction on the sieve ${ }^{19,20}$. The obtained hexahydrate sodium tripolyphosphate has the bulk density $>1.03 \mathrm{~kg} /$ $\mathrm{dm}^{3}$. STPP with the increased bulk density $0.95-1.03 \mathrm{~kg} /$ $\mathrm{dm}^{3}$ and suitable granulation can be also produced with the use of one or two fluidized beds ${ }^{21,22}$. Some methods are used to produce sodium tripolyphosphate having medium bulk density (about $\left.0.87 \mathrm{~kg} / \mathrm{dm}^{3}\right)^{23,24}$.

\section{EXPERIMENTAL}

The proposed method allows obtaining the granulated sodium tripolyphosphate with the desirable granulation, high bulk density and the high content of Form I or Form II with a chemical method. To $100 \mathrm{~g}$ of sodium ortho- and pyrophosphates mixture (the product of spray drying of the sodium phosphates solution in one industrial unit) 42 $\mathrm{g}$ of water and next $100 \mathrm{~g}$ of STPP powder $(<0.25 \mathrm{~mm})$ were added. The mixture was mixed for 15 minutes in the laboratory mortar and calcined for $1 \mathrm{~h}$ in the laboratory chamber kiln. STPP with a high content of Form I was obtained at the temperature of $550^{\circ} \mathrm{C}$ and with a high content of Form II at $400^{\circ} \mathrm{C} .178 \mathrm{~g}$ (Form I) and $182 \mathrm{~g}$ (Form II) of the „heavy” sodium tripolyphosphate were obtained, respectively.

The phase composition of the used material, the charges and products were identified with the X-ray method using Philips X'Pert diffractometer with the graphite monochromator PW W 1752/00. The thermal analysis was conducted with the 2960 Simultaneous DTA-DTG TA Instruments. The sieve analysis was made for the mixture of phosphates and for the milled STPP according to standard ${ }^{25}$. The bulk density was marked according to standard ${ }^{\mathbf{2 6}}$ for individual grain fractions and the mixture 


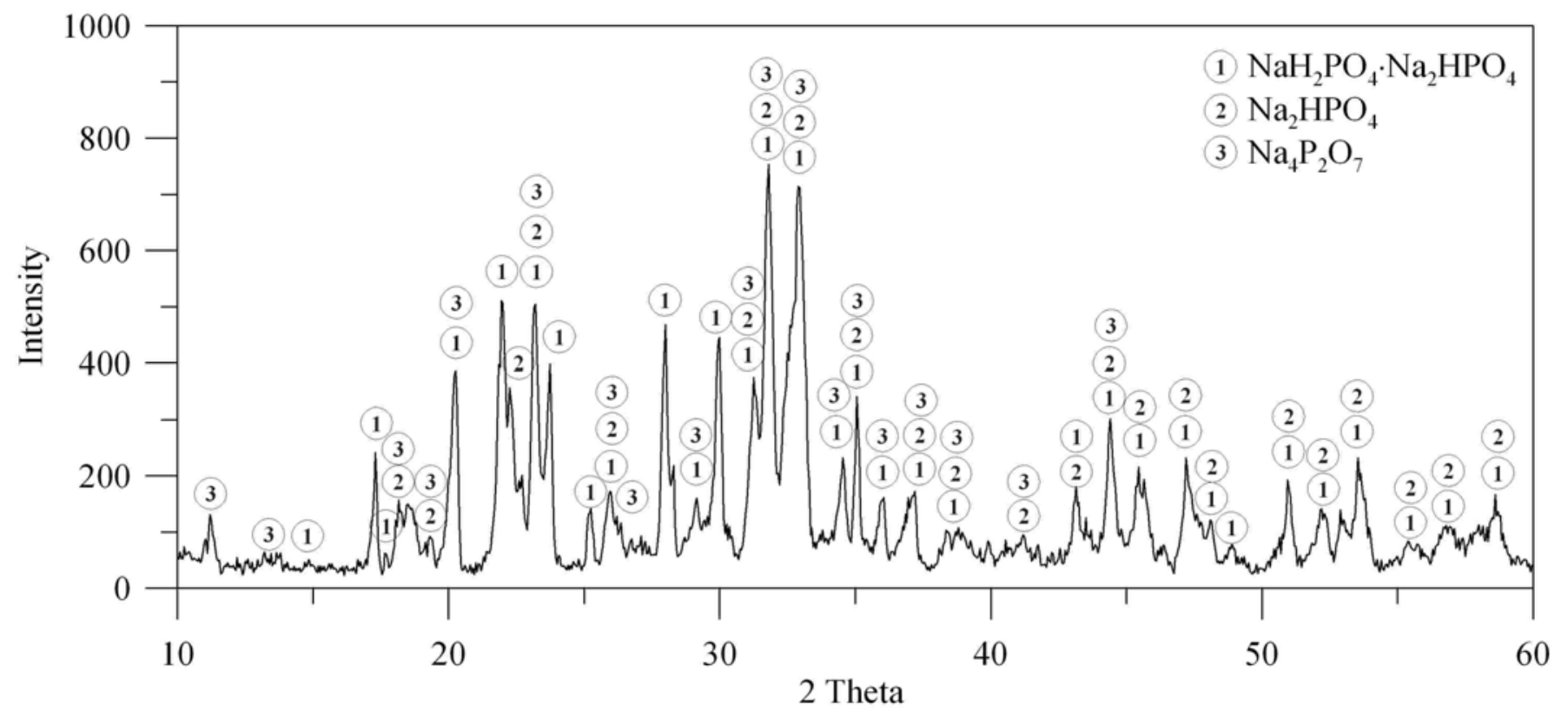

Figure 1. The X-ray diffraction of the dried sodium phosphates

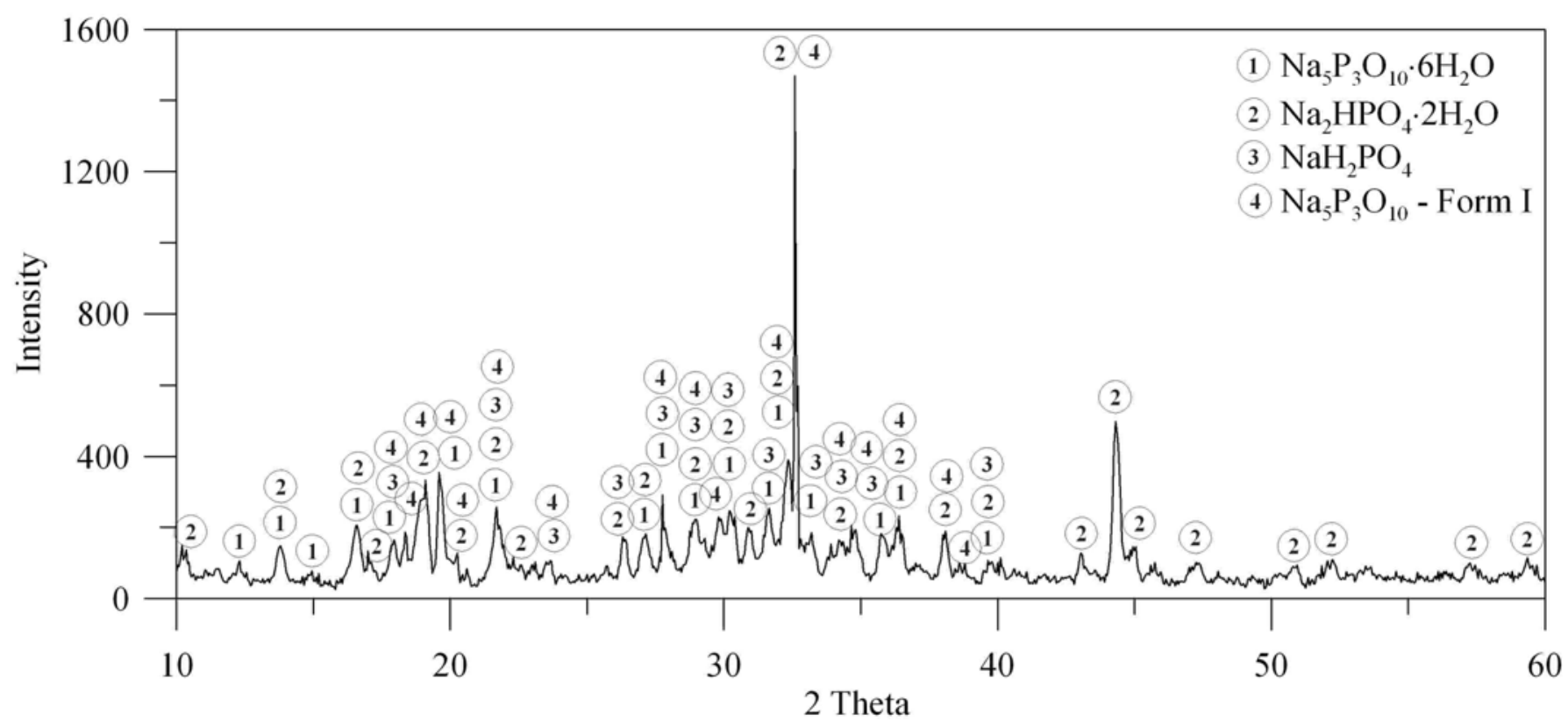

Figure 2. The X-ray diffraction of the mixture of the dried sodium phosphates with water and the powder of the STPP Form I

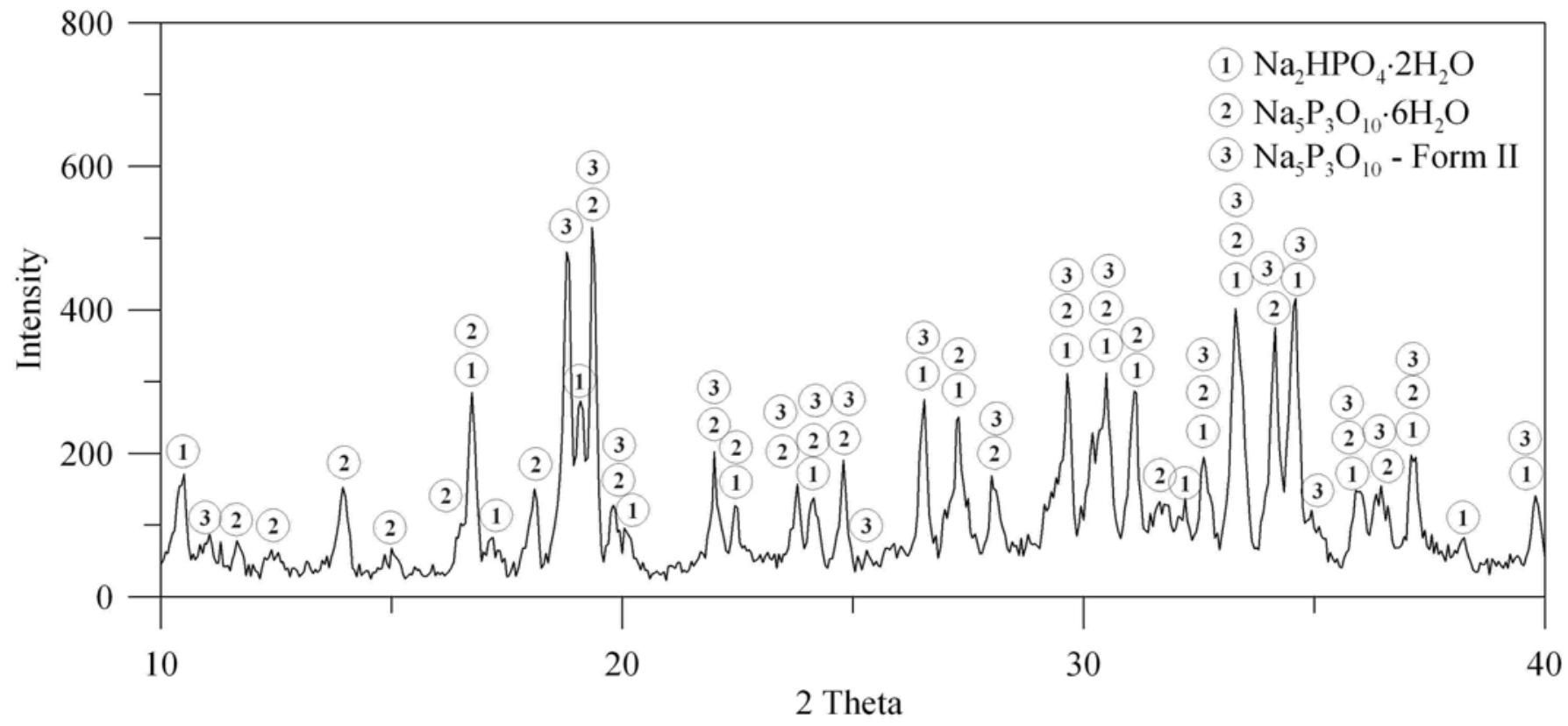

Figure 3. The X-ray diffraction of the mixture of the dried sodium phosphates with water and the powder of the STPP Form II 


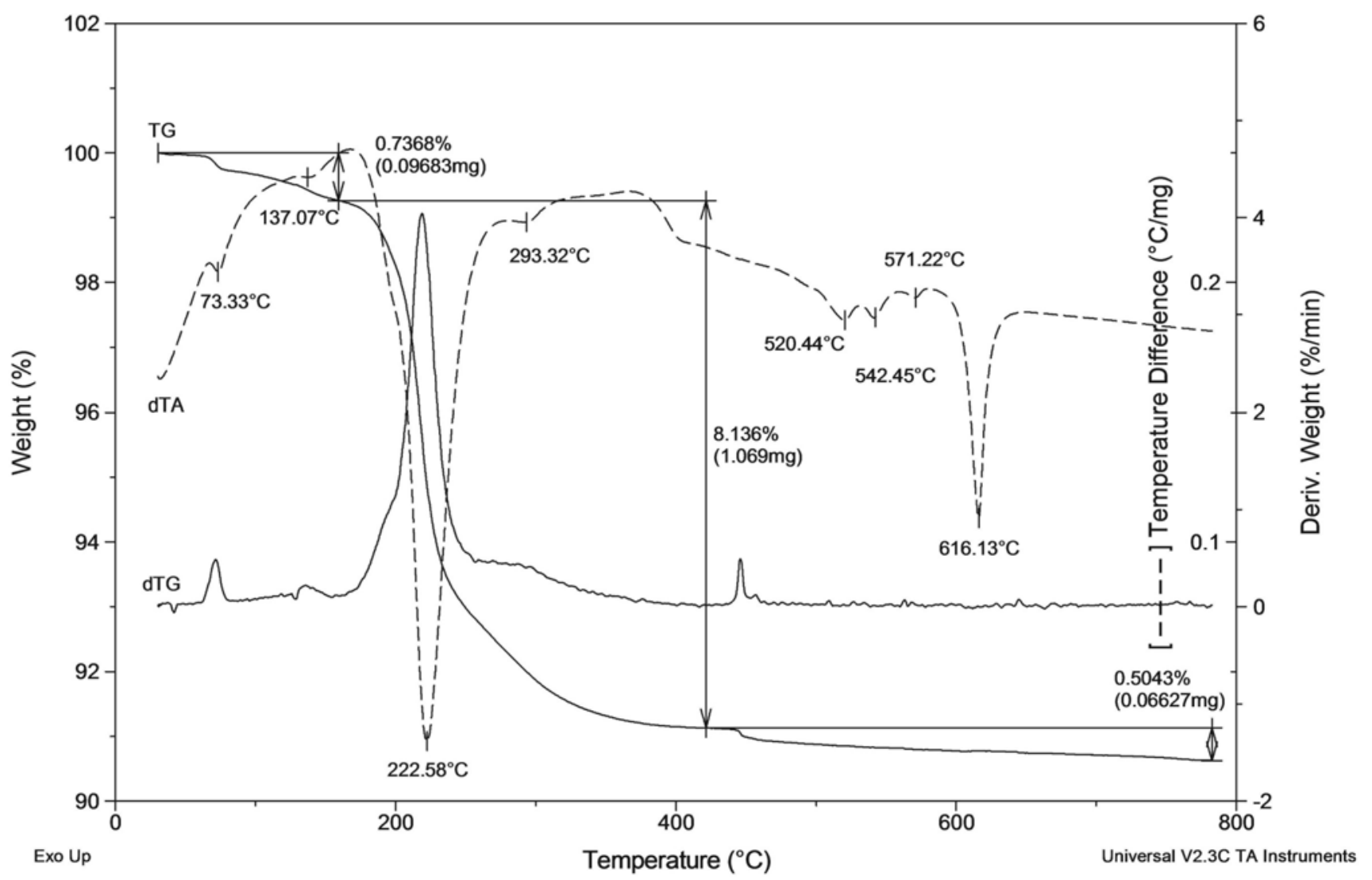

Figure 4. The TGA-DTA analysis of the dried sodium phosphates

Size: $19.1316 \mathrm{mg}$

TGA-DTA

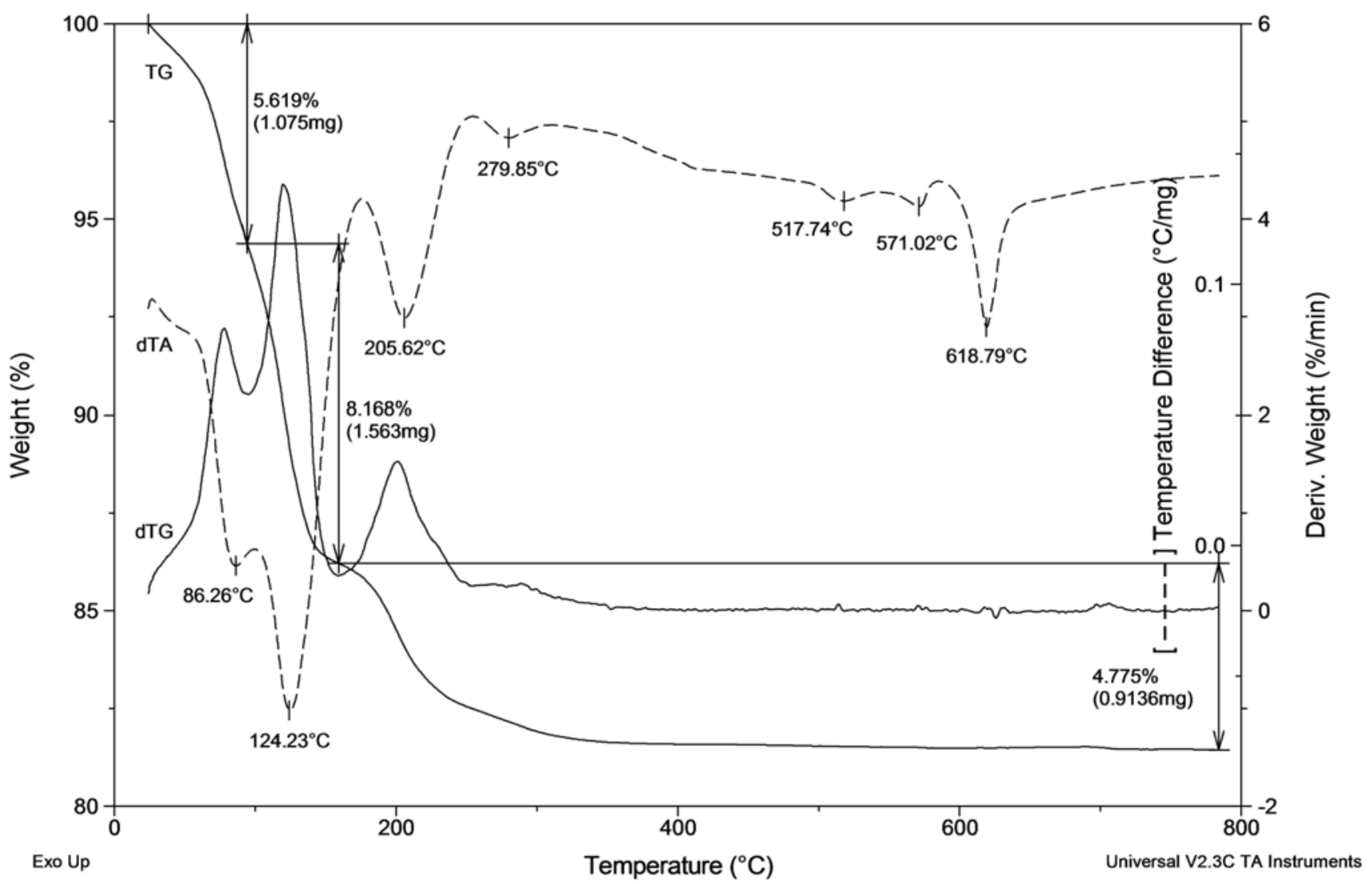

Figure 5. The TGA-DTA analysis of the mixture of the dried sodium phosphates with water and the powder of the STPP Form I 
of these fractions, specified $\operatorname{in}^{27}$ as: fraction above 1.00 $\mathrm{mm}-10 \%$, fraction between 0.85 to $1.00 \mathrm{~mm}-20 \%$, 0.60 to $0.85 \mathrm{~mm}-5 \%, 0.25$ to $0.60 \mathrm{~mm}-58 \%{ }^{27}$.

The grain size and the bulk density of the produced „heavy” sodium tripolyphosphate were compared with the sieve analysis and the bulk density of the reference samples, having lower bulk density. The low density of STPP with a high content of Form I was produced in the calcining process of sodium phosphates mixture at $550^{\circ} \mathrm{C}$ within 1 hour. Form II was obtained during the same process but at $400^{\circ} \mathrm{C}$.

\section{RESULTS AND DISCUSSION}

The basic crystalline phase of the investigated materials is the double salt $\mathrm{NaH}_{2} \mathrm{PO}_{4} \cdot \mathrm{Na}_{2} \mathrm{HPO}_{4}$. The double salt is accompanied by sodium orthophosphates $\left(\mathrm{Na}_{2} \mathrm{HPO}_{4}\right)$ and sodium pyrophosphates $\left(\mathrm{Na}_{4} \mathrm{P}_{2} \mathrm{O}_{7}\right)$ (Figure 1). The hydrated salts $\mathrm{Na}_{5} \mathrm{P}_{3} \mathrm{O}_{10} \cdot 6 \mathrm{H}_{2} \mathrm{O}$, $\mathrm{Na}_{2} \mathrm{HPO}_{4} \cdot 2 \mathrm{H}_{2} \mathrm{O}$, and $\mathrm{NaH}_{2} \mathrm{PO}_{4}, \mathrm{Na}_{5} \mathrm{P}_{3} \mathrm{O}_{10}-$ Form I are the effects of the addition of water and the recycling powder of STPP Form I (Figure 2). $\mathrm{Na}_{5} \mathrm{P}_{3} \mathrm{O}_{10} \cdot 6 \mathrm{H}_{2} \mathrm{O}$, $\mathrm{Na}_{2} \mathrm{HPO}_{4} \cdot 2 \mathrm{H}_{2} \mathrm{O}$ and $\mathrm{Na}_{5} \mathrm{P}_{3} \mathrm{O}_{10}-$ Form II appeared after the addition of water and STPP Form II (Figure 3 ).

Thermal analysis indicated that phase changes were comparable for all the three charges (Figures $4-6$ ). The differences occur at temperatures $70-140^{\circ} \mathrm{C}$. Moisture was removed at the temperature of $80^{\circ} \mathrm{C}$. The chemically bounded water was removed at $110-140^{\circ} \mathrm{C}$. The orthophosphates transformation into pyrophosphates was took place at $190-230^{\circ} \mathrm{C}$. Sodium tripolyphosphate Form II was formed near the temperature of $280^{\circ} \mathrm{C}$. At $>450^{\circ} \mathrm{C}$ Form II quite quickly transformated into Form I. Figures 7 and 8 show the XRD analyses of STPP with high bulk density. Form I was obtained at $550^{\circ} \mathrm{C}$ and Form II at $400^{\circ} \mathrm{C}$.

Figures $9-13$ show the results of the sieve analyses of the sodium phosphates, the low bulk density STPP (Form I and Form II) and high bulk density STPP (Form I and Form II). The maximum value of the plus mesh $(51.96 \%)$ for the dried sodium phosphates was in the sieve of 0.25 $\mathrm{mm}$ (Figure 9). Most grains $>0.25 \mathrm{~mm}$ appeared also in the case of low bulk density STPP Form I - 51.94\% (Figure 10). Similar results were obtained for the low bulk density STPP Form II $-56.44 \%>0.25 \mathrm{~mm}$ (Figure 11). The maximum value of the plus mesh for the high bulk density STPP Form I (36.32\%) and Form II (30.70\%) was $<0.25 \mathrm{~mm}$ (Figures 12 and 13 ).

The curves minus mesh are similar for the dried sodium phosphates and both forms of low bulk density STPP (Figures 9-11). The low-density sodium tripolyphosphate contains more of the fine-grained dust. The curves minus mesh are different for the high density STPP (Figures 12 and 13). The high bulk density sodium tripolyphosphate (Form I and Form II) has very continuous grain-size distribution. The mixture of the dried phosphates has the highest quantity $94.33 \%$ of the fraction $>0.25 \mathrm{~mm}$. After calcining the content of the granulated fraction decreased to $83.79 \%$ for Form I and $82.27 \%$ for Form II. The quantity of the fraction $>0.25 \mathrm{~mm}$ in the samples pre-

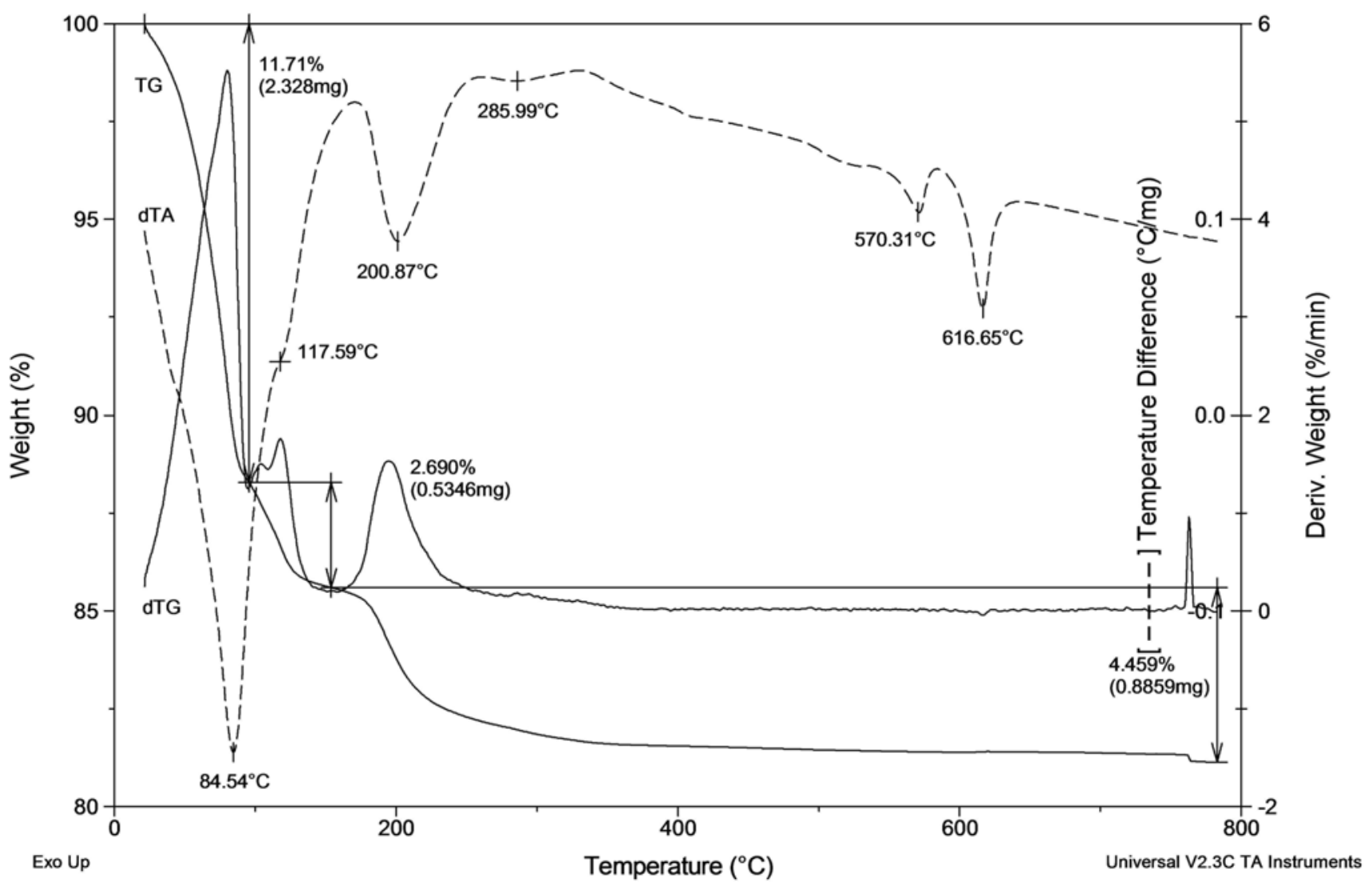

Figure 6. The TGA-DTA analysis of the mixture of the dried sodium phosphates with water and the powder of the STPP Form 


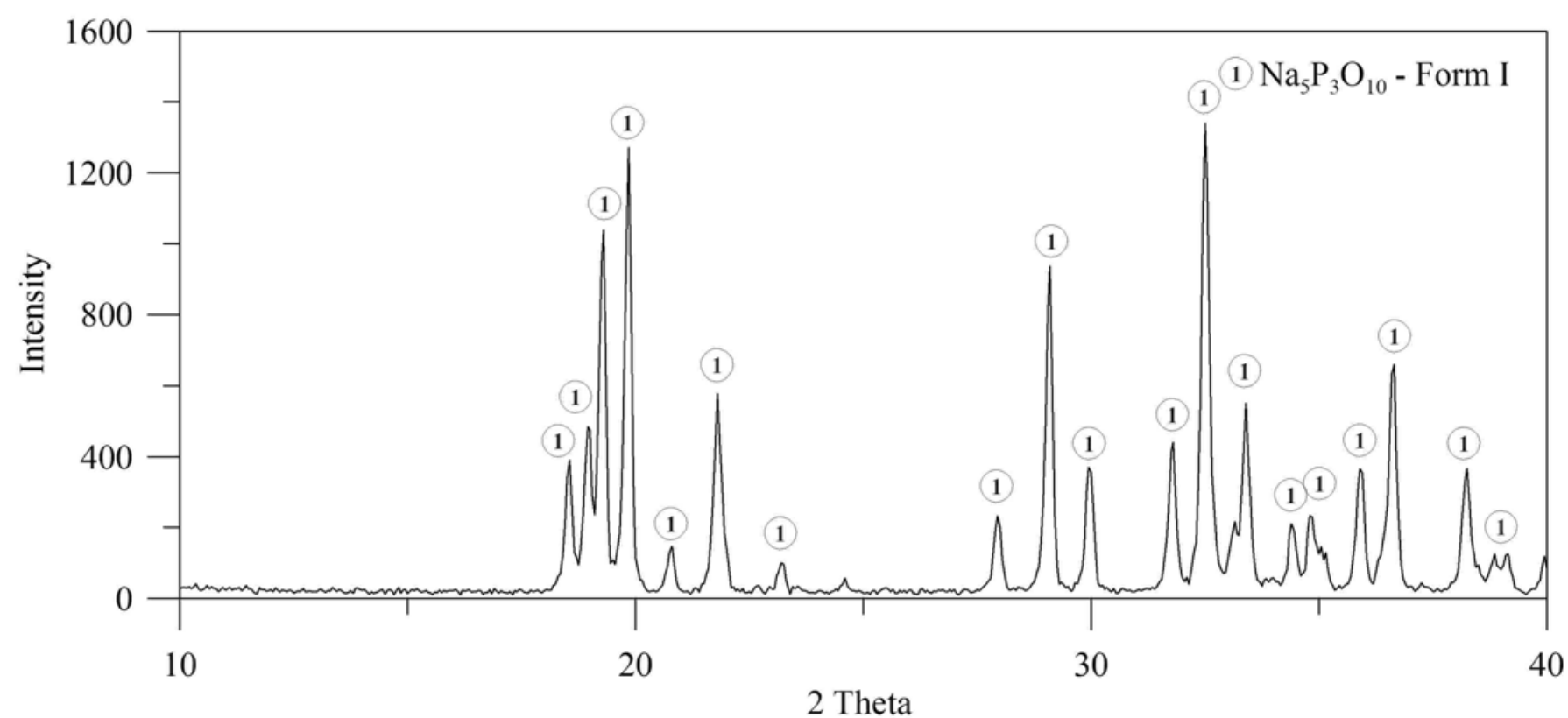

Figure 7. The X-ray diffraction of the high bulk density STPP Form I

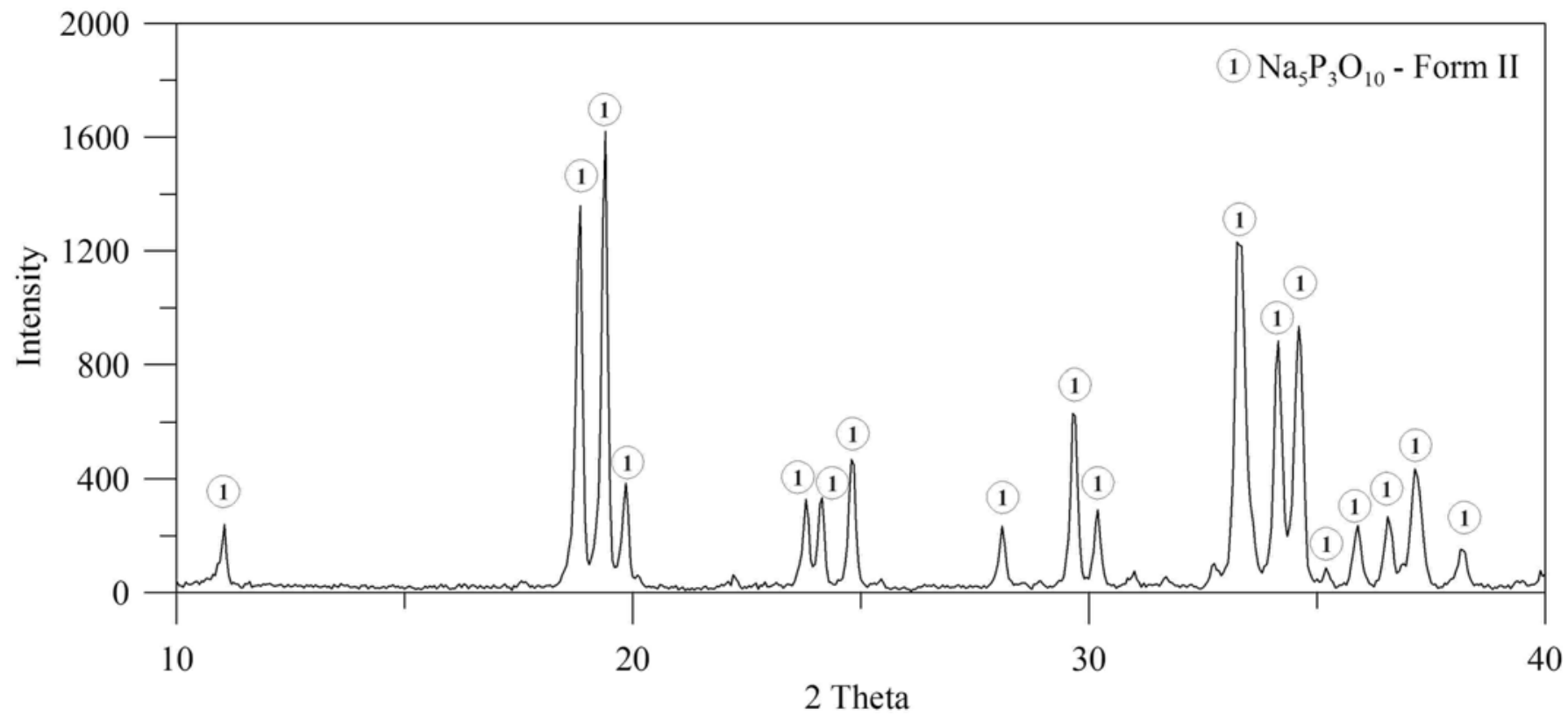

Figure 8. The X-ray diffraction of the high bulk density STPP Form II

pared with the worked out method is $63.68 \%$ for Form I and $69.30 \%$ for Form II.

The bulk density value of the sodium phosphates, the low-density sodium tripolyphosphate and the high-density STPP are shown in Table 1.

The bulk density of the classical granulated sodium phosphates is about $0.42 \mathrm{~kg} / \mathrm{dm}^{3}$. The fraction with the highest bulk density $\left(0.50 \mathrm{~kg} / \mathrm{dm}^{3}\right)$ is the fraction with the grain size $<0.25 \mathrm{~mm}$. The granulated STPP has the bulk density: $0.45 \mathrm{~kg} / \mathrm{dm}^{3}$ for Form I and $0.46 \mathrm{~kg} / \mathrm{dm}^{3}$ for Form II. Grain fraction $0.25-0.60 \mathrm{~mm}$ being in the granulated product in the quantity $58 \%$, has the bulk density $\sim 0.43 \mathrm{~kg} / \mathrm{dm}^{3}$ (for both forms of STPP). Fraction $<0.25 \mathrm{~mm}$ has the bulk density about $0.54 \mathrm{~kg} / \mathrm{dm}^{3}$ for Form I and $0.52 \mathrm{~kg} / \mathrm{dm}^{3}$ for Form II.

The worked out method of the granulated sodium tripolyphosphate production increased the bulk density to $1.05 \mathrm{~kg} / \mathrm{dm}^{3}$ (Form I) and to $1.07 \mathrm{~kg} / \mathrm{dm}^{3}$ (Form II). The fraction with the highest bulk density had the grain size between $0.25-0.60 \mathrm{~mm}\left(0.95 \mathrm{~kg} / \mathrm{dm}^{3}\right.$ Form I and 1.00 $\mathrm{kg} / \mathrm{dm}^{3}$ Form II).

\section{CONCLUSIONS}

The paper presents the worked out chemical method of the production of the high bulk density sodium tripolyphosphate $\left(>1.04 \mathrm{~kg} / \mathrm{dm}^{3}\right)$. The product has the high content of Form I or Form II. The fine-grained dust is recovered into the process.

Sodium tripolyphosphate obtained by the calcining of the spray dried sodium phosphates, has the form of ,empty shells". This results in the profitable grain size distribution but in the low bulk density (about $0.45 \mathrm{~kg} / \mathrm{dm}^{3}$ ). The bulk density of sodium tripolyphosphate was increased by means of preparing the mixture of the dried sodium phosphates, recycled STPP powder and water in specific proportions and calcining this mixture for 1 hour at the temperature of $400^{\circ} \mathrm{C}$ and $550^{\circ} \mathrm{C}$ (to obtain the proper STPP 


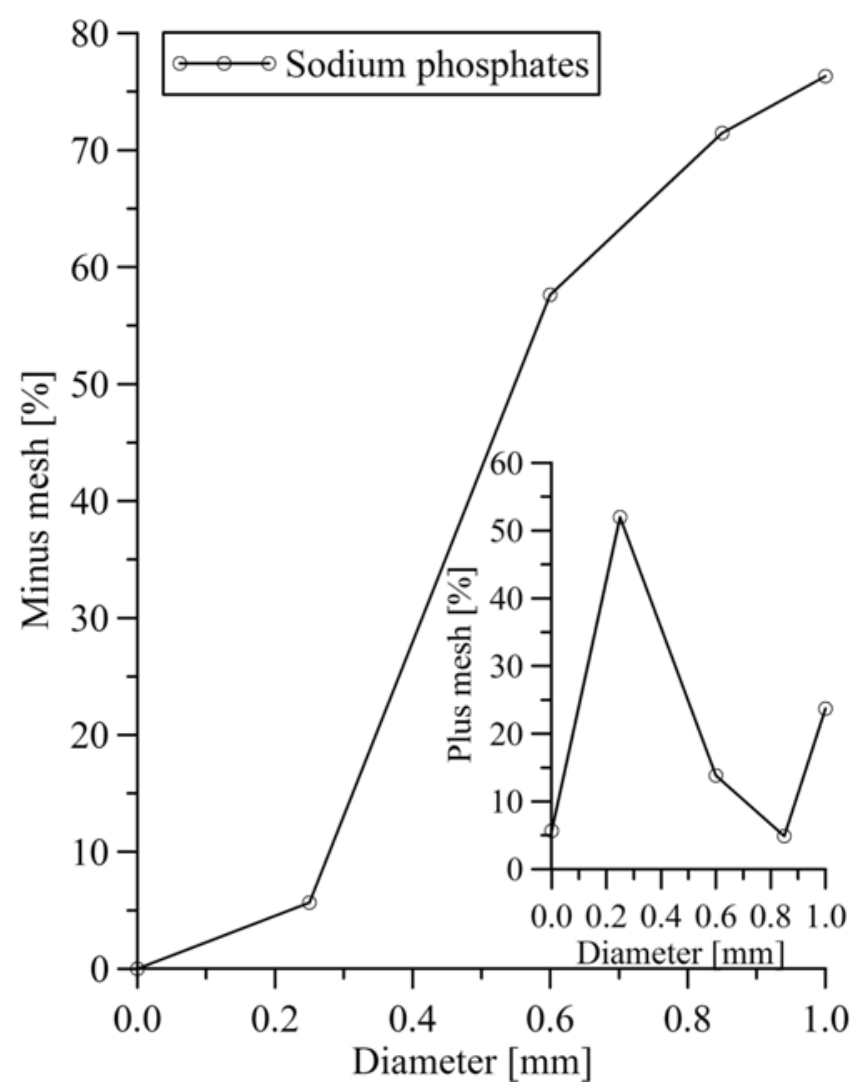

Figure 9. The curves plus mesh and minus mesh of the sodium phosphates

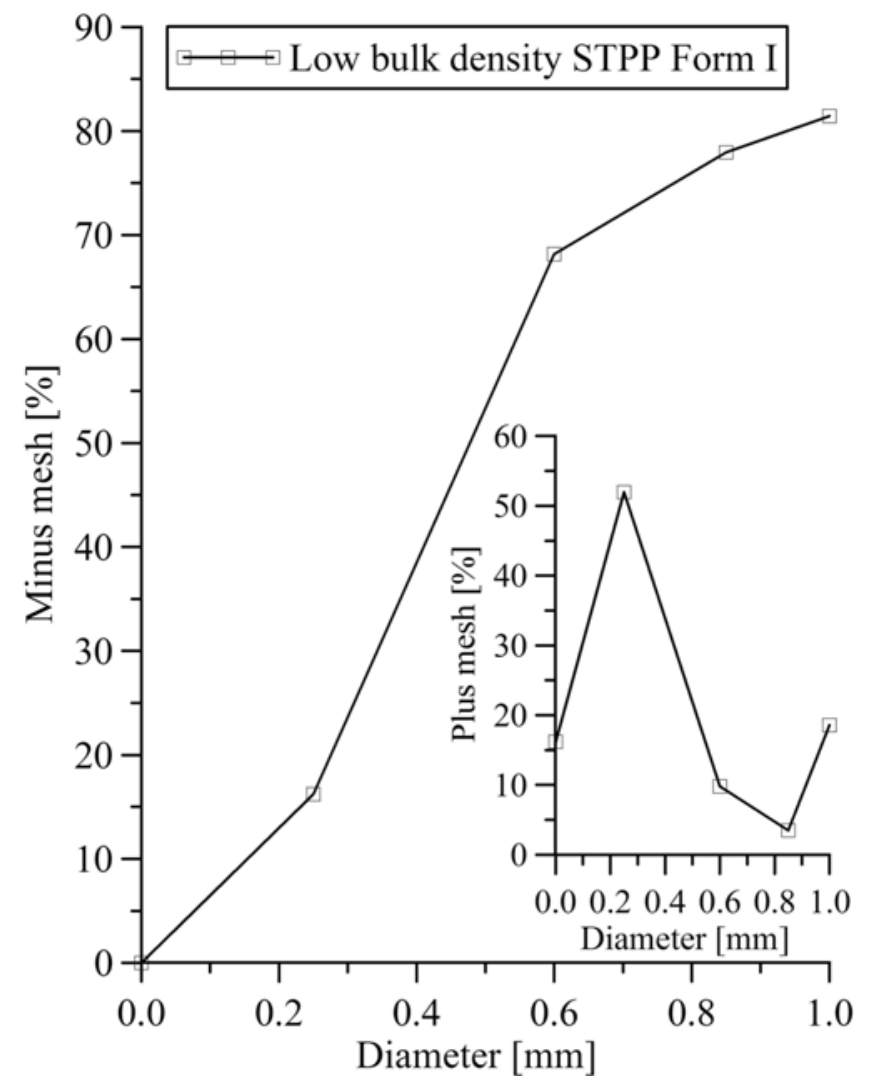

Figure 10. The curves plus mesh and minus mesh of the low bulk density STPP Form I

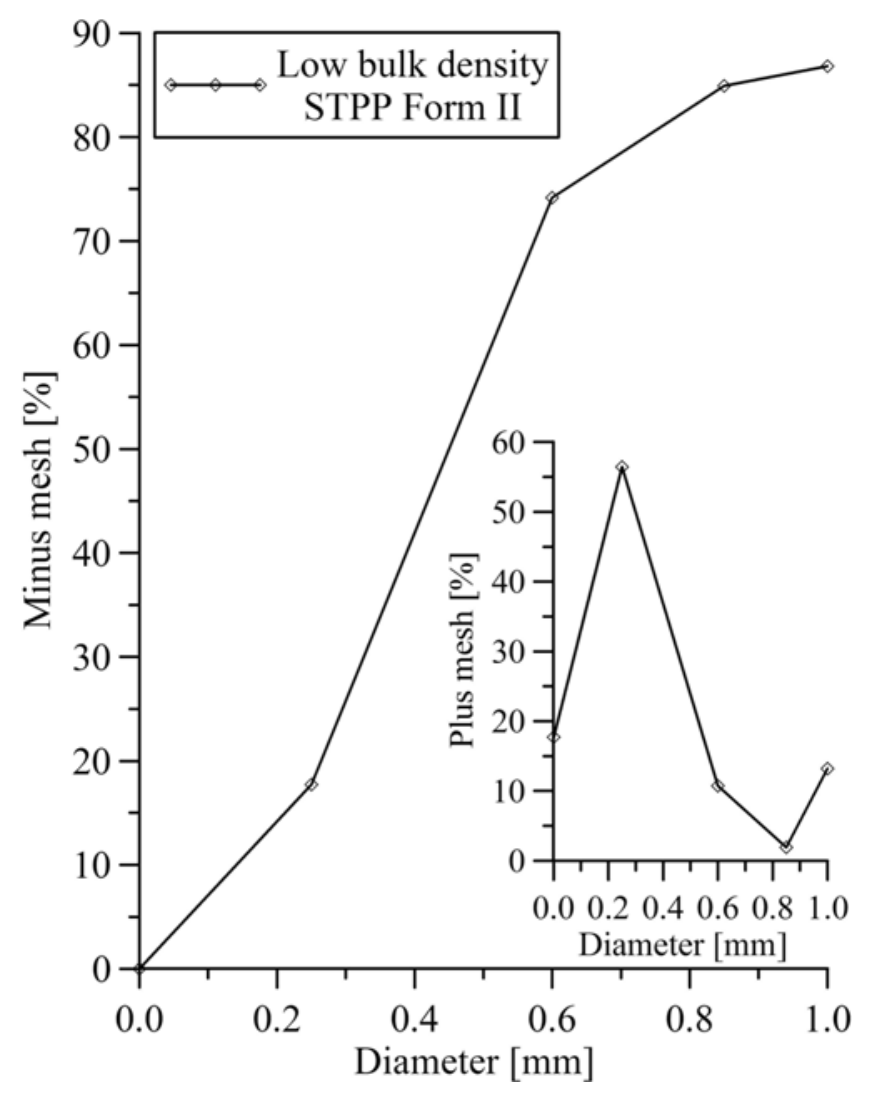

Figure 11. The curves plus mesh and minus mesh of the low bulk density STPP Form II

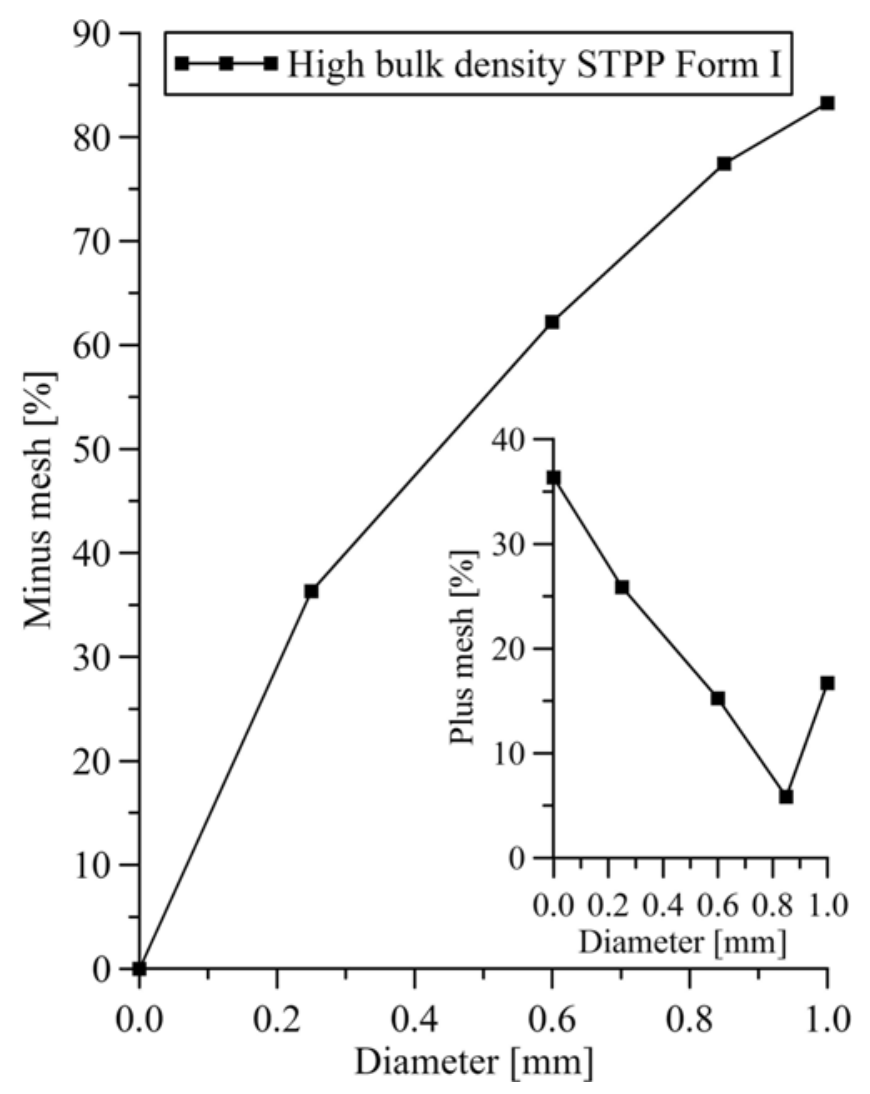

Figure 12. The curves of plus and minus mesh of the high bulk density STPP Form I 
Table 1. Result of the bulk density analysis

\begin{tabular}{|c|c|c|c|}
\hline \multirow{2}{*}{ Sample } & Grain fraction & Bulk density of the fraction & Bulk density of the granulated product \\
\hline & {$[\mathrm{mm}]$} & {$\left[\mathrm{kg} / \mathrm{dm}^{3}\right]$} & {$\left[\mathrm{kg} / \mathrm{dm}^{3}\right]$} \\
\hline \multirow{5}{*}{ Dried sodium phosphates } & Above 1.00 & $0.3413 \pm 0.0035$ & \multirow{5}{*}{$0.4227 \pm 0.0026$} \\
\hline & $0.85-1.00$ & $0.3553 \pm 0.0013$ & \\
\hline & $0.60-0.85$ & $0.3307 \pm 0.0035$ & \\
\hline & $0.25-0.60$ & $0.4053 \pm 0.0013$ & \\
\hline & Below 0.25 & $0.5007 \pm 0.0035$ & \\
\hline \multirow{5}{*}{ STPP Form I with low bulk density } & Above 1.00 & $0.3247 \pm 0.0047$ & \multirow{5}{*}{$0.4467 \pm 0.0047$} \\
\hline & $0.85-1.00$ & $0.3383 \pm 0.0017$ & \\
\hline & $0.60-0.85$ & $0.3677 \pm 0.0017$ & \\
\hline & $0.25-0.60$ & $0.4327 \pm 0.0026$ & \\
\hline & Below 0.25 & $0.5453 \pm 0.0035$ & \\
\hline \multirow{5}{*}{ STPP Form II with low bulk density } & Above 1.00 & $0.4004 \pm 0.0023$ & \multirow{5}{*}{$0.4650 \pm 0.0034$} \\
\hline & $0.85-1.00$ & $0.3393 \pm 0.0028$ & \\
\hline & $0.60-0.85$ & $0.3768 \pm 0.0018$ & \\
\hline & $0.25-0.60$ & $0.4300 \pm 0.0012$ & \\
\hline & Below 0.25 & $0.5170 \pm 0.0013$ & \\
\hline \multirow{5}{*}{ STPP Form I with high bulk density } & Above 1.00 & $0.8595 \pm 0.0032$ & \multirow{5}{*}{$1.0481 \pm 0.0062$} \\
\hline & $0.85-1.00$ & $0.8620 \pm 0.0030$ & \\
\hline & $0.60-0.85$ & $0.8773 \pm 0.0034$ & \\
\hline & $0.25-0.60$ & $0.9497 \pm 0.0053$ & \\
\hline & Below 0.25 & $0.9030 \pm 0.0057$ & \\
\hline \multirow{5}{*}{ STPP Form II with high bulk density } & Above 1.00 & $0.8930 \pm 0.0030$ & \multirow{5}{*}{$1.0701 \pm 0.0031$} \\
\hline & $0.85-1.00$ & $0.9007 \pm 0.0013$ & \\
\hline & $0.60-0.85$ & $0.9079 \pm 0.0018$ & \\
\hline & $0.25-0.60$ & $1.0029 \pm 0.0040$ & \\
\hline & Below 0.25 & $0.9897 \pm 0.0030$ & \\
\hline
\end{tabular}

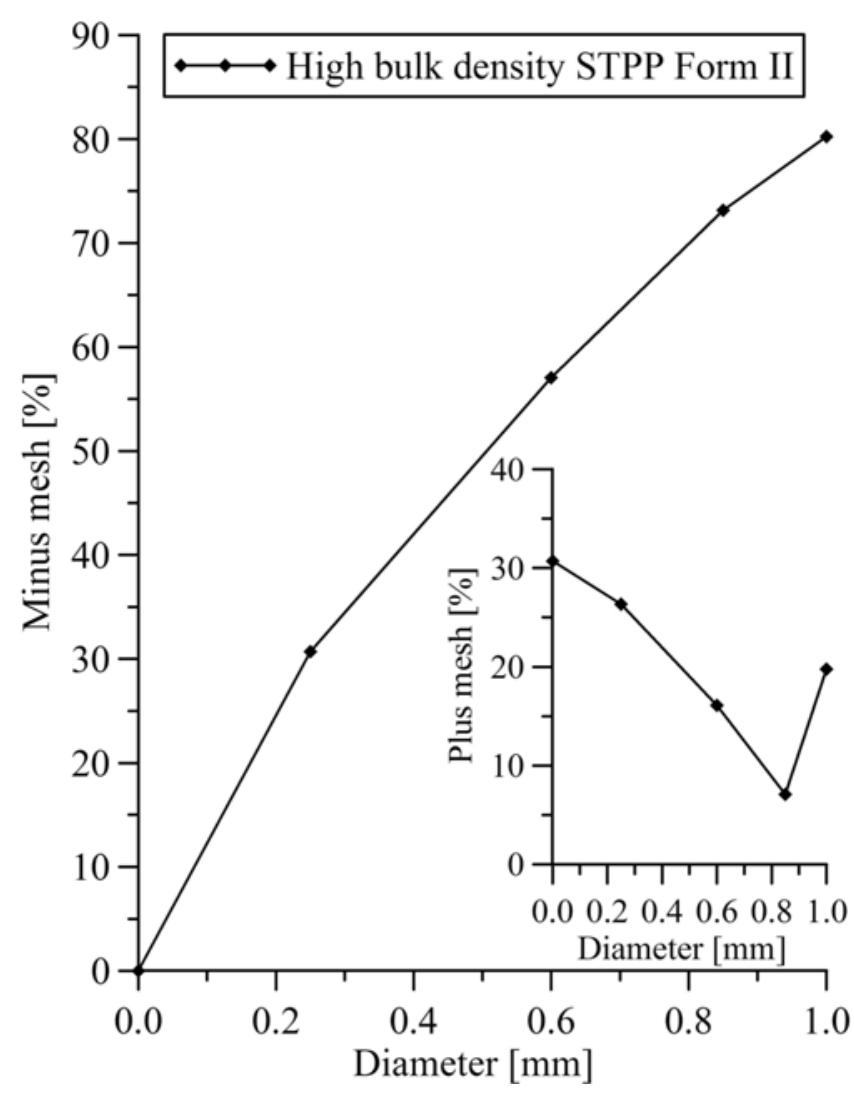

Figure 13. The curves of plus and minus mesh of the high bulk density STPP Form II

form) in the chamber kiln. This method allows producing the granular sodium tripolyphosphate with the high bulk density $\left(1.04-1.07 \mathrm{~kg} / \mathrm{dm}^{3}\right)$ and a high content of Form I or Form II, respectively.

\section{LITERATURE CITED}

1. Commission of the european communities (2007, may). Report from the commission to the council and the european parliament. Pursuant to Article 16 of Regulation (EC) No 648/ 2004 of the European Parliament and of the Council of 31 March 2004 on detergents, concerning the use of phosphates. Retrieved July 14, 2008, from http://ec.europa.eu/enterprise/ chemicals/legislation/detergents/reports/ com_2007_234_en.pdf

2. Tynan, M. \& Westwell, J. R. (2007). European Patent No. 1240297 B1. Paris, D.C.: European Patent Office.

30. Imaizumi, Y., Yamashita, H. \& Kubota, T. (2007). European Patent No. 1534812 B1. Paris, D.C.: European Patent Office.

4. Barthel, W., Duffels, A., Flleccia, S. \& Timmann, A. (2007). U.S. Patent No. 2007/0244026 A1. Washington, D.C.: U.S. Patent and Trademark Office.

5. CEEP (2007, July). Function of phosphates in detergents. Retrieved July 14, 2008, from http://www.ceep-phosphates.org

6. CEEP (2007, August). Phosphates in Automatic Dishwasher Detergents. Retrieved July 14, 2008, from http:// www.ceep-phosphates.org

7. Köhler, J. (2006, May). Detergent Phosphates: an EU Policy Assessment. Retrieved July 14, 2008, from http:// www.businesschemistry.org/20062.htm

8. CEEP. CEEP Press Releases concerning phosphates and detergent wash performance. Retrieved July 14, 2008, from http://www.ceep-phosphates.org

9. Dall'Acqua, S., Fawer, M., Fritschi, R. \& Allenspach, C. (1999, March). Life Cycle Inventories for the Production of Detergent Ingredients. Int. J. LCA 4(4) Retrieved July 14, 2008, from SpringerLink database on the World Wide Web: http://www.springerlink.com. DOI: 10.1007/BF02979499.

10. International Association for Soaps, Detergents and Maintenance Products (2004). A.I.S.E. Laundry Sustainability Project (LSP). Retrieved July 14, 2008, from http://www.aise.eu 
11. Nitta, H., Yamashita, H. \& Salto, J. (2006). U.S. Patent No. 6,992,055 B1. Washington, D.C.: U.S. Patent and Trademark Office.

12. Saouter, E., Van Hoof, G., Pittinger, Ch. A. \& Feijtel, T. C. J. (2001). The Effect of Compact Formulations on the Environmental Profile of Northern European Granular Laundry Detergents. Part I: Environmental Risk Assessment. Int. J. LCA. 6(6), 1 - 10. DOI: 10.1065/lca2001.06.057.1.

13. Saouter, E., Van Hoof, G., Feijtel, T. C. J. \& Owens, W. (2002). The Effect of Compact Formulations on the Environmental Profile of Northern European Granular Laundry Detergents. Part II: Life Cycle Assessment. Int. J. LCA . 7(1), 27 - 38. DOI: 10.1065/lca2001.06.057.2.

14. Gorlin, P., Zyzyck, L. \& Jakubicki, G. (2001). U.S. Patent No. 6,191,089 B1. Washington, D.C.: U.S. Patent and Trademark Office.

15. Krieg, J. (2006). European Patent No. 1669438 A1. Paris, D.C.: European Patent Office.

16. Hensler, P. I., Church, D. F. \& Beger, R. W. (1981). U.S. Patent No. 4,255,274. Washington, D.C.: U.S. Patent and Trademark Office.

17. Highfill, L. \& Lannert, K. (1994). U.S. Patent No. 5294424. Washington, D.C.: U.S. Patent and Trademark Office.

18. Van Wazer, J. R. (1958). Phosphorus and Its Compounds, New York, USA: Interscience Publishers.

19. Marschall, H. L., Alto, P. \& Coykendall, J. W. (1967). U.S. Patent No. 3,338,671. Washington, D.C.: U.S. Patent and Trademark Office.

20. Zorska, E., Cholewa, J., Gadomski, Z. \& Olech, M. (2007). Polski Patent No. 196166 B1. Urząd Patentowy Rzeczpospolitej Polskiej.

21. Sproul, J. S. \& Lapple, W. C. (1969). U.S. Patent No. 3,437,434. Washington, D.C.: U.S. Patent and Trademark Office.

22. Sproul, J. S., McCarthy, M. J. \& Lapple, W. C. (1969). U.S. Patent No. 3,437,433. Washington, D.C.: U.S. Patent and Trademark Office.

23. Cadwallader, G. W. \& Highfill, L. A. (1993). U.S. Patent No. 5,215,731. Washington, D.C.: U.S. Patent and Trademark Office.

24. Kowalski, Z., Kijkowska, R., Pawłowska-Kozińska, D. \& Wzorek Z. (2002). Sodium Tripolyphosphate and others Condensed Sodium Phosphates Production Methods. Pol. J. Chem. Tech. 4(3), 27 - 33.

25. Polski Komitet Normalizacji, Miar i Jakości (1993). Polska Norma: Metody badań soli fosforowych. Oznaczenie pozostałości na sicie. PN-93/C-84300/26.

26. Polski Komitet Normalizacji, Miar i Jakości (1980). Polska Norma: Oznaczanie gęstości nasypowej. PN-80/C04532.

27. Procter \& Gamble. Manufacturing Standards - European Operations (1998). Raw material specification. Granular sodium tripolyphosphate, high bulk density. 10072234. 